\title{
Commentary: Is the brain spared when the heart is broken?
}

Check for updates

\author{
Shabnam Peyvandi, MD, MAS, ${ }^{a}$ and Patrick S. McQuillen, MD $^{\mathrm{b}}$
}

\footnotetext{
From the ${ }^{\mathrm{a} D i v i s i o n}$ of Pediatric Cardiology, Department of Pediatrics and Epidemiology \& Biostatistics and ${ }^{\mathrm{b}} \mathrm{Di}-$ vision of Critical Care, Department of Pediatrics, Benioff Children's Hospital, University of California San Francisco, San Francisco, Calif.

Disclosures: Authors have nothing to disclose with regard to commercial support.

Received for publication Feb 4, 2019; accepted for publication Feb 4, 2019; available ahead of print March 14, 2019.

Address for reprints: Shabnam Peyvandi, MD, MAS, 550 16th St, San Francisco, CA 94158 (E-mail: shabnam. peyvandi@ucsf.edu).

J Thorac Cardiovasc Surg 2019;157:1994-5

$0022-5223 / \$ 36.00$

Copyright (c) 2019 by The American Association for Thoracic Surgery

https://doi.org/10.1016/j.jtcvs.2019.02.017
}

Neurodevelopmental impairments are common in survivors of complex congenital heart disease. ${ }^{1}$ Studies with magnetic resonance imaging have identified neonatal brain injury $^{2}$ and delays in brain development beginning in the third trimester of fetal life. ${ }^{3,4}$ The etiology of fetal brain immaturity in congenital heart disease (CHD) is an ongoing topic of debate, with many invoking chronic fetal hypoxia as the cause ${ }^{5}$ and others suggesting that cerebral blood flow or nutrition, specifically glucose delivery to the brain, is impaired. ${ }^{6}$ In this issue of the Journal, Lawrence and colleagues, ${ }^{7}$ investigators from the Children's Hospital of Philadelphia, report their study in which they sought to determine the underlying etiology of delayed brain development in utero. With the innovative Extra-uterine Environment for Neonatal Development (EXTEND) system, Lawrence and colleagues ${ }^{7}$ tested the hypothesis that isolated chronic hypoxia in utero would alter brain development in the fetal lamb.

Fetal lambs at a gestational age equivalent to the early third trimester in human fetal development were exteriorized and placed into the EXTEND system under normoxic or hypoxic conditions, with umbilical flow held constant. The fetal lambs remained in the system for 3 weeks under these conditions, after which brains were analyzed for growth, development, and injury and compared with those of gestation-matched control animals.

The main findings from this study demonstrate that the fetal lambs under hypoxic conditions had diminished cortical folding, decreased neuronal density, increased vascularity, and reduced myelin integrity, all suggesting delayed development. Of note, overt brain injury was not noted in any group.

These findings are intriguing and thought provoking. We can certainly agree that in this animal model with a structurally normal heart, isolated chronic hypoxia is detrimental to brain development, akin to that in the growth-restricted fetus. This may, however, be just one piece of the puzzle. It is challenging to apply these findings to the human fetus

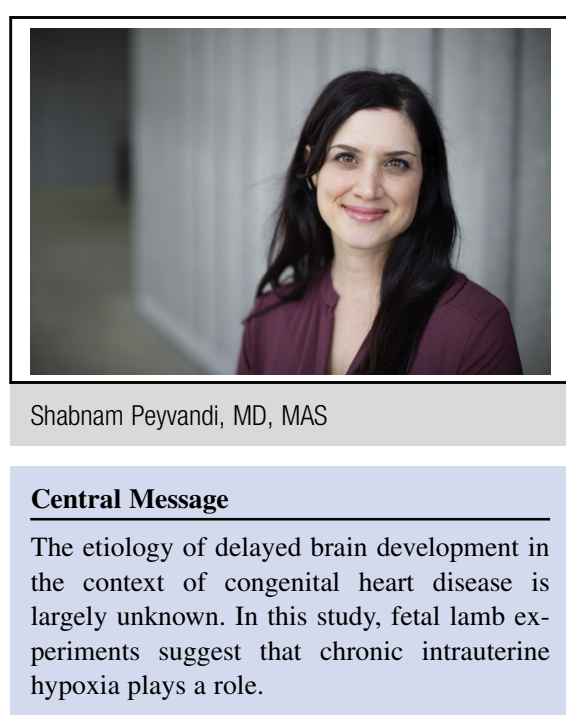

See Article page 1982.

with CHD. There is tremendous variability in both cerebral blood flow and oxygen content of blood flow to the brain depending on the subtype of CHD. As pointed out by Rudolph, ${ }^{6}$ fetuses with hypoplastic left heart syndrome have inadequate perfusion of the brain that "compromises not only oxygen supply but also delivery of metabolic substrates, predominantly glucose." This study design does not exclude the possibility that glucose influences the developing brain, because varying degrees of glucose delivery or perfusion to the brain were not studied as oxygen was. In addition, genetic variations may play a critical role in neurodevelopment among patients with CHD. ${ }^{8}$

The absence in this model of in utero brain injury, as measured by cell death, provides a unique opportunity to study further the complex relationship between delayed brain development and injury. Although postnatal studies have suggested brain immaturity as the substrate for injury, the myriad of risk factors in the postnatal period complicates this conclusion; thus, the chicken and egg debate continues. Assessment of cell death alone, however, may not fully account for other pathologic processes, including inflammation and gliosis.

In conclusion, Lawrence and colleagues ${ }^{7}$ are to be congratulated on this elegant and innovative experiment. This work is moving us forward in our quest for better understanding of the developing brain and for improved neurodevelopmental outcomes in our patients. 


\section{References}

1. Gaynor JW, Stopp C, Wypij D, Andropoulos DB, Atallah J, Atz AM, et al; International Cardiac Collaborative on Neurodevelopment (ICCON) Investigators. Neurodevelopmental outcomes after cardiac surgery in infancy. Pediatrics. 2015;135:816-25.

2. McQuillen PS, Barkovich AJ, Hamrick SE, Perez M, Ward P, Glidden DV, et al. Temporal and anatomic risk profile of brain injury with neonatal repair of congenital heart defects. Stroke. 2007;38(2 Suppl):736-41.

3. Miller SP, McQuillen PS, Hamrick S, Xu D, Glidden DV, Charlton N, et al. Abnormal brain development in newborns with congenital heart disease. $\mathrm{N} \mathrm{Engl}$ J Med. 2007;357:1928-38.

4. Limperopoulos C, Tworetzky W, McElhinney DB, Newburger JW, Brown DW, Robertson RL Jr, et al. Brain volume and metabolism in fetuses with congenital

heart disease: evaluation with quantitative magnetic resonance imaging and spectroscopy. Circulation. 2010;121:26-33.

5. Sun L, Macgowan CK, Sled JG, Yoo SJ, Manlhiot C, Porayette P, et al. Reduced fetal cerebral oxygen consumption is associated with smaller brain size in fetuses with congenital heart disease. Circulation. 2015;131:1313-23.

6. Rudolph AM. Impaired cerebral development in fetuses with congenital cardiovascular malformations: is it the result of inadequate glucose supply? Pediatr Res. 2016;80:172-7.

7. Lawrence KM, McGovern PE, Mejaddam A, Rossidis AC, Baumgarten H, Kim A, et al. Chronic intrauterine hypoxia alters neurodevelopment in fetal sheep. J Thorac Cardiovasc Surg. 2019;157:1982-91.

8. Homsy J, Zaidi S, Shen Y, Ware JS, Samocha KE, Karczewski KJ, et al. De novo mutations in congenital heart disease with neurodevelopmental and other congenital anomalies. Science. 2015;350:1262-6. 